\title{
INFECÇÃO HOSPITALAR RELACIONADA AOS VISITANTES E ACOMPANHANTES EM AMBIENTES CRÍTICOS
}

\author{
HOSPITAL INFECTION RELATED TO VISITORS AND \\ ACCOMPANITIES IN CRITICAL ENVIRONMENTS
}

\author{
Aline Facchi ${ }^{1}$, Karonllay Fonseca Nonato ${ }^{1}$, Rafaela Bramatti Oliveira ${ }^{2 *}$ \\ ${ }^{1}$ Centro Universitário Fundação Assis Gurgacz - FAG. ${ }^{2}$ Mestre em Enfermagem, Professora do \\ Curso de Enfermagem do Centro Universitário Fundação Assis Gurgacz - FAG. \\ * Autor correspondente: rafaelabramatti@fag.edu.br, https://orcid.org/0000-0003-1797-842X
}

DOI: 10.35984/fjh.v2i1.162

\begin{abstract}
RESUMO
A infecção hospitalar (IH) é um dos grandes agravantes da saúde no país. Umas das principais medidas de prevenção e controle das infecções encontram-se na higienização correta das mãos e na paramentação adequada, antes da entrada em ambientes críticos como à UTI. Relacionado aos visitantes/acompanhantes, é fundamental certificar-se de que sejam devidamente orientados pelos profissionais de saúde, quanto à forma adequada de se prevenir em relação às infecções. Este artigo realizou o método de pesquisa qualitativa e quantitativa de cunho exploratório-descritivo, transversal, onde foram observados, analisados e computados os dados colhidos com visitantes/acompanhantes de uma Unidade de Terapia Intensiva do Oeste do Paraná. Foi aplicado um questionário com questões abertas e fechadas para obtenção de dados sobre as suas percepções, com o consentimento dos participantes. A pesquisa contou com a participação de 10 visitantes/acompanhantes de pacientes internados na Unidade de Terapia Intensiva, com faixa etária 18 a 50 anos. Com a análise destes resultados, foi possível observar que somente $50 \%$ dos participantes receberam as informações de maneira adequada, 62 \% receberam tais informações de enfermeiros que expressam a importância da orientação, paramentação, e até mesmo da higienização adequada das mãos, resultando em uma recuperação gradativa e satisfatória aos envolvidos. Palavra-chave: Infecção; Infecção hospitalar; Higiene das mãos.
\end{abstract}

\begin{abstract}
ABSTRATC
Hospital infection $(\mathrm{IH})$ is one of the major health aggravations in the country. One of the main infection prevention and control measures is proper hand hygiene and proper dressing before entering critical environments such as the ICU. Regarding visitors/companions, it is essential to make sure that they are properly advised by health professionals, as to the proper way to prevent infections. This article carried out the qualitative and quantitative research method of exploratory-descriptive, cross-sectional nature, where we observed, analyzed and computed the data collected with visitors/companions of an Intensive Care Unit in the Western of Paraná. A questionnaire with open and closed questions was applied to obtain data on their perceptions, with the consent of the participants. The research was attended by 10 visitors / companions of patients admitted to the Intensive Care Unit, aged 18 to 50 years. With the analysis of these results, it was observed that only $50 \%$ of the participants received the information adequately, $62 \%$ received this information from nurses who express the importance of orientation, dressing, and even proper hand hygiene, resulting in a gradual and satisfactory recovery to those involved.
\end{abstract}

Keyword: Infection; Nosocomial infection; Hand hygiene. 


\section{INTRODUÇÃO}

A Infecção hospitalar pode ser conceituada como aquelas contraídas durante a hospitalização/internação prolongada ou não de um paciente. Manifesta-se no período intra-hospitalar (02 semanas a 02 meses) devido à grande manipulação de dispositivos (cateteres e sondas) ou posteriormente à sua alta (02 a 03 semanas). A resposta imunológica do paciente em terapia intensiva frente ao processo infeccioso é deficiente, os mecanismos de defesa estão comprometidos pela doença motivadora da hospitalização ou pelas intervenções necessárias para o diagnóstico e seu tratamento (PEREIRA, 2000).

Para reduzir os níveis de infecção, os hospitais devem adotar medidas habituais de prevenção e controle de infecções, através das precauções padrões (AGUIAR, LIMA e SANTOS, 2008).

As precauções padrões podem ser definidas como um conjunto de medidas empregadas no atendimento a todos os pacientes hospitalizados, independentemente de seu estado infectado ou não, na manipulação de equipamentos e artigos contaminados ou sob suspeita de contaminação, almejando reduzir a transmissão de agentes patogênicos. Nesse grupo, estão incluídos os equipamentos de proteção individual (EPI'S) (máscaras, óculos, protetor facial, luvas, avental) e a higienização adequada das mãos (HM) (COUTO et al., 2009).

A maneira mais simples e eficaz de evitar a infecção hospitalar em um ambiente repleto de micro-organismos resistentes aos antibióticos, e causadores de diferentes doenças é a lavagem adequada das mãos (COUTO, 2009). Esta é, de maneira geral, uma orientação dada e reforçada pela equipe de enfermagem, que passa a ser valorizada pelos acompanhantes, pois é introduzida a eles como algo importante e de imprescindível dispensa. (LIMA et al., 2011).

O objetivo do presente artigo é identificar se os visitantes/acompanhantes de pacientes internados na Unidade de Terapia Intensiva (UTI) recebem orientações adequadas em relação aos cuidados necessários, quais são esses cuidados, quais profissionais realizaram e em qual momento estes visitantes/acompanhantes receberam essas informações.

\section{METODOLOGIA}

Trata-se de uma pesquisa de campo com abordagem qualitativa e quantitativa de cunho exploratório-descritivo. Fora realizada após a observação do comportamento e rotinas de visitantes/acompanhantes na sua entrada e permanência em ambientes hospitalares críticos, e entregue após questionário para obtenção de dados.

O projeto de pesquisa foi aprovado pelo Comitê de Ética, com o número de parecer 3.479.669. Os dados foram coletados após a obtenção do Termo de Consentimento Livre e Esclarecido de cada participante. A pesquisa envolveu 10 visitantes/ acompanhantes de ambos os sexos com idades entre 18 a 50 anos, escolhidos de maneira aleatória, presentes na UTI de uma instituição hospitalar do Oeste do Paraná. Os dados foram coletados no dia 10 de agosto de 2019 no período matutino, por meio de um questionário formulado e entregue pelas autoras do artigo, no qual constavam 10 perguntas abertas e fechadas.

O questionário desenvolvido pelas autoras foi aplicado durante a permanência de acompanhantes na UTI, e com visitantes, após horário de visita estipulado pela instituição, no hall de entrada da UTI. Todos os participantes abordados participaram 
prontamente da pesquisa. Os dados obtidos foram armazenados, submetidos a formulação de tabelas utilizando o programa Excel, e avaliados com o intuito de apontar o que fora obtido através da aplicação do mesmo.

\section{RESULTADOS E DISCUSSÃO}

A pesquisa contou com a participação de 10 visitantes/acompanhantes. Desses, $30 \%$ tinham uma grande experiência em relação à paramentação e à lavagem adequada das mãos, pois seus entes queridos já se encontravam em uma internação prolongada (03 meses). Entretanto, os 70\% restantes dos participantes estavam enfrentando seu primeiro contato em um ambiente crítico (primeira visita).

Para melhor compreensão, os resultados foram separados por categorias: a primeira buscou compreender qual o conhecimento e informações recebidas pelos visitantes/acompanhantes, a segunda quais profissionais repassaram as informações e a terceira em qual local essas informações foram transmitidas. A seguir, iniciamos com a primeira categoria.

Tabela1. Dados colhidos com participantes através do questionário aplicado.

\begin{tabular}{|c|c|c|}
\hline \multirow{2}{*}{ Questões } & \multicolumn{2}{|c|}{ Respostas } \\
\hline & SIM & NÃO \\
\hline $\begin{array}{l}\text { 1- Você foi orientado que está sujeito a transmitir algum tipo de infecção } \\
\text { para o paciente internado? }\end{array}$ & 7 & 3 \\
\hline 2- Você sabe a importância da higienização das mãos? & 9 & 1 \\
\hline 3- Você teve orientação de como higienizar às mãos de maneira correta? & 5 & 5 \\
\hline 4- Você sabe o que são EPI'S? & 10 & 0 \\
\hline 5- Foi orientado a usá-los na UTI? & 4 & 6 \\
\hline $\begin{array}{l}\text { 8- Você achou importante as informações que foram passadas para } \\
\text { você? }\end{array}$ & 7 & 3 \\
\hline $\begin{array}{l}\text { 9- Você realizou todos os procedimentos que foram passados para } \\
\text { você? }\end{array}$ & 9 & 1 \\
\hline $\begin{array}{l}\text { 10- A partir de hoje você realizara as medidas que foram passadas a } \\
\text { você? }\end{array}$ & 10 & 0 \\
\hline
\end{tabular}

Segundo a tabela acima podemos observar que a maioria dos acompanhantes reconhecem a importância da lavagem das mãos e a paramentação adequada em locais críticos, entretanto nem sempre estão sendo orientados corretamente referente à essas técnicas, dificultando assim a sua execução, podendo transmitir microorganismos aos pacientes destes locais (SIQUEIRA et al., 2006).

Visitantes/acompanhantes que adentram em ambientes críticos sem higienização correta das mãos, paramentação adequada (aventais, máscaras, luvas, etc.), ou com pertences (bolsas, celulares, etc.), propiciam o aumento das chances de aquisição de infecção advinda de meios externos, transmitindo impurezas, ocasionando assim piora no seu caso clínico que já se encontra delicado. Essas informações corroboram a pesquisa feita por (DOMINGUES et al., 1999).

A higienização das mãos é a medida mais simples, fácil e eficaz para a prevenção de infecções relacionadas ao paciente/visitante; recomenda-se que as mãos sejam higienizadas sempre antes de tocar nos pacientes e após este contato. Trata-se de um processo de remoção das sujidades, suor, bactérias, oleosidades, pelos, entre outros tipos de micro-organismos invisíveis a olho nu (VIANA \& WHINTAKER, 2011). 
A aceitação dessa prática possui uma grande importância no percentual de infecção hospitalar, pelo fato de que a maioria dos micro-organismos está ligado a microbiota transitória das mãos, sendo adquirida pelo contato direto com as pessoas, materiais colonizados ou infectados. Os mesmos podem ser facilmente eliminados através de uma adequada lavagem das mãos, gerando a diminuição de bactérias. (COELHO et al., 2011).

Apesar de ser clara a importância da higienização das mãos na prevenção e controle das infecções, a adesão dessa prática permanece em níveis baixos. Outro fator importante é que as pias mal localizadas e o conhecimento inadequado dos profissionais de saúde sobre a maneira de higienizá-las tornam deficientes as informações passadas aos visitantes/acompanhantes nas unidades de assistência à saúde (PRADO e MARAN, 2014).

Com as devidas orientações prestadas aos visitantes/acompanhantes, podemos minimizar os possíveis índices de infecções hospitalares, facilitando assim 0 tratamento de pacientes internados em ambientes críticos.

$\mathrm{Na}$ próxima tabela, encontram-se a categoria que expressa em qual local os visitantes/acompanhantes receberam as orientações, e quais profissionais lhes informaram sobre o assunto destacado.

Tabela 2. Qual o local e profissionais que transmitiram as informações aos participantes.

\begin{tabular}{|c|c|c|c|}
\hline Questões & & Respostas & \\
\hline \multirow{2}{*}{ 6- Onde foram passadas as orientações? } & Entrada UTI & Beira leito & Outros \\
\hline & 5 & 1 & 1 \\
\hline \multirow{2}{*}{$\begin{array}{l}\text { 7- Quais profissionais lhe deram essas } \\
\text { informações? }\end{array}$} & Enfermeiro & Médicos & Auxiliar \\
\hline & 6 & 2 & 1 \\
\hline
\end{tabular}

Conforme a tabela 2, 62\% dos participantes receberam as orientações na entrada da UTI, antes do contato com o paciente internado, $25 \%$ citaram que receberam informações por meio próprios - internet, livros e entre outros, ou buscaram informações fora do local hospitalar - e 13\% foram orientados ao lado de seus familiares, já teriam adentrado sem as informações necessárias.

O momento correto para orientar visitantes/acompanhantes seria na internação de seus familiares, em local apropriado (setor de internamento, sala de espera), repassar todas as orientações necessárias, explicar rotinas e normas da instituição de saúde, sanar todas as dúvidas existentes, explicar sobre infraestrutura, horários de alimentações, entre outros (DIBAl e CADE, 2008).

Orientar os visitantes/acompanhantes antes de sua entrada em ambientes críticos apresenta um grande aumento na proteção relacionada à prevenção de infecções. Visitantes/acompanhantes que realizam a higienização correta das mãos e a paramentação adequada antes de sua entrada nesses ambientes estão de alguma forma protegendo seus familiares.

O profissional mais apontado pelos participantes da pesquisa em relação às orientações prestadas foram os enfermeiros(as), pois $67 \%$ dos participantes citaram que foram orientados por Enfermeiros(as), 22\% foram orientados por Médicos(as) em conversas eventuais, $11 \%$ foram orientados por Auxiliares de serviços gerais da instituição.

O profissional enfermeiro tem o papel fundamental nas orientações prestadas aos visitantes/acompanhantes. Demonstrar a importância da lavagem adequada das mãos a paramentação correta com a utilização de aventais, gorros, máscaras, entre 
outros, tem diminuído níveis de infecções hospitalares em setores como a UTI. As orientações passadas por esses profissionais têm grande valia no dia a dia de acompanhantes/visitantes (SILVA e COLTRIN, 2006).

Assistir a família do paciente hospitalizado é função do profissional enfermeiro e sua equipe multiprofissional. Características peculiares deste papel incluem a habilidade de reconhecer e conviver com a família na situação de doença, incluindoa no planejamento dos cuidados. Acredita-se que ao valorizar a presença da família no ambiente crítico, o enfermeiro propicia a melhora do estado emocional do paciente hospitalizado, desempenha um papel singular no cuidado (OLIVEIRA et al., 2011).

No ambiente critico, para que aconteça uma comunicação efetiva entre enfermeiro-família, é necessário que a equipe escute as dúvidas dos visitantes/acompanhantes e as responda da melhor maneira possível (OLIVEIRA et al., 2011).

O profissional enfermeiro frente aos visitantes/acompanhantes é de extrema importância em relação às orientações sobre a lavagem das mãos, horários de visitas, procedimentos realizados ao decorrer do período de internação, entre outros. Acolher esse público se torna algo de grande importância, e sanar as dúvidas propicia um aumento na prevenção e cuidado com os pacientes.

\section{CONCLUSÃO}

Foi possível observar que a maioria dos visitantes/acompanhantes receberam as informações necessárias, porém em alguns momentos houveram lacunas. Episódios em que profissionais de saúde não tiveram o cuidado necessário no quesito de orientar, devido à rotina exacerbada do setor. Podemos melhorar essas orientações com a atenção redobrada nos colaboradores da instituição, buscando melhorar a educação permanente de servidores, para que as informações passadas aos visitantes/acompanhantes sejam de fontes confiáveis. O profissional enfermeiro é o principal responsável por essas orientações, revelando, portanto, a sua importância neste processo.

Após o momento da visita, as autoras trouxeram orientações verbais e demonstrativas aos visitantes/acompanhantes, sobre a importância extrema da lavagem das mãos e a colocação de aventais em locais como a UTI, com a finalidade de evitar infecções cruzadas entre pacientes, acompanhantes/visitantes e diminuindo assim o tempo de internação hospitalar dos pacientes. Para a instituição na qual a pesquisa fora desenvolvida, o estudo apontou que podemos diminuir os níveis de infecções aos pacientes que se encontram internados, por meio de orientações adequadas, educação em saúde e empatia com os visitantes/acompanhantes.

\section{REFERÊNCIAS}

AGUIAR, D. F.; LIMA, A. B. G.; SANTOS, R. B. Uso das precauções padrão na assistência de enfermagem. Escola Anna Nery Revista de Enfermagem. 2008 Vol. 12, no 3, p. 571-75. DOI: 10.1590/S1414-81452008000300027

COUTO, R. C. [et al.] Infecção hospitalar e outras complicações não infecciosas da doença: epidemiologia, controle e tratamento. 4aㅡ ed. Rio de Janeiro 2009.

DIBAI, M. B. S.; CADE, N. V. A experiencia do acompanhante de paciente internado em instituição hospitalar. Revista Enfermagem. 2009 Vol. 17, n⒈ Rio de 
Janeiro. Disponível em: http://www.revenf.bvs.br/pdf/reuerj/v17n1/v17n1a16.pdf. Acesso em 01 setembro. 2019.

DOMINGUES, C. I.; SANTINI, I.; SILVA, V. E. F. Orientações aos familiares em uti: dificuldades ou falta de sistematização? Revista Escola Enfermagem. 1999 Vol. 33, no1. São Paulo. Disponível em: https://www.revistas.usp.br/reeusp/article/view/41084. Acesso em: 01 setembro. 2019. DOI: 10.1590/S0080-62341999000100005

LIMA, F. M. O.; OLIVEIRA, C. R.; BATISTA, D. Q. G.; FORMIGA, C. C. A.; LIMA, C. Importância da lavagem das mãos no controle da infecção hospitalar para acompanhantes de pacientes internos de hospital. UFPB. Disponível em: http://www.prac.ufpb.br/enex/trabalhos/6CCMDPSPROBEX2013374.pdf. Acesso em: 20 agosto. 2019.

PEREIRA, M. S.; PRADO, M. A.; SOUSA, J. T.; TIPPLE, A. F. V.; SOUZA, A. C. S. Revista Eletrônica de Enfermagem (online), Controle da infecção hospitalar em unidade de terapia intensiva: desafios e perspectivas. Goiânia, p. 01-09, out-dez. 2000. Disponível em: http://www.revistas.ufg.br/index.php/fen. Acesso em: 22 agosto. 2019.

PRADO, M. F.; MARAN, E. Desafios ao uso das preparações alcoólicas para higienização das mãos nos serviços de saúde. UEP, PARANAVAI-PR, 2014. Disponível em: $\quad$ http://www.scielo.br/scielo.php?script=sci arttext\&pid=S141481452014000300544\&lang=pt. Acesso em: 23 agosto. 2019. DOI: 10.5935/14148145.20140078

SILVA, N. D.; CONTRIN, L. M. Orientações do enfermeiro dirigidas aos familiares dos pacientes internados na uti no momento da visita. Arq. Cienc. Saúde. p 148152, jul.-set. 2007. Disponível em: http://repositorio-racs.famerp.br/racs ol/vol-143/IIIDDD204.pdf. Acesso em: 31 agosto. 2019. 